\title{
Globalization and Distorted Development: In Search of a System Perspective for Sustainability
}

\author{
Darío Menanteau-Horta \\ Center for Rural Sociology and Community Analysis, \\ University of Minnesota, USA \\ dmenante@umn.edu
}

\section{Introduction}

The controversial relationship between globalization and social development still dominates the intellectual and socio-political debate of our days. The $21^{\text {st }}$ century has evolved, so far, without an agreement between those who promise prosperity and opportunities in an expanded and international world market and those who claim that globalization, as it has been carried on today, is a negative force for peace, equity, and social development.

While the most visible effects of globalization include the internationalization of the world economy, the expansion of markets, and a growing interconnectedness among countries, the process also carries major consequences for social development. In fact, the most serious consequence, especially in Third World countries, is the inability of national governments to invest in programs of social welfare. Policies of national development are being reduced as the role of the state is being diminished. Today, social stratification has become international while inequality remains global.

As demonstrated by today's financial and economic international crisis, current patterns of globalization reaffirm a growing interdependence of the world economy, modern technology, and communications. The same process, however, carries little or no change in old conditions of international stratification, global inequality, and insufficient efforts for social development.

This paper examines three main issues pertinent to globalization: 
(1) First, the notion that globalization is a new phenomenon and a different paradigm is highly questionable. Less developed countries have had long histories of dependent relationships and vulnerability to external political and economic powers.

(2) Globalization has produced conditions of "distorted development" characterized by economic growth without social development.

(3) More functional and sustainable relationships between globalization and social development are explored and discussed. The paper reviews sociocybernetic principles of the "Viable System" suggested by Stafford Beer.

\section{Some Historical Patterns}

The expansion of markets and protection of power zones have influenced international trade throughout history, resulting in international relations of domination and dependency. A number of developing countries, for example, have had a long history of dependent relationships with international markets. From its origins followed by long years of conquest and colonization, the economies of these developing nations have been export-oriented and vulnerable to external power conditions. Even after 200 years of independence, Latin American societies, for example, have been characterized by a rigid social stratification leading to inequalities, political conflicts, and fragile democratic systems.

Latin America is important in studying globalization because most of the countries of the region have already made major efforts to participate competitively in the globalization process. Their success or failure within a global economy, therefore, may provide valuable examples to the rest of the world. Although most of Latin America offers open economies to the global market, internal conditions in those countries are still affected by high poverty rates, pronounced income inequality, and persistent social exclusion. Of course, these conditions are not new in Latin America. The question, however, remains whether globalization is something new or rather a known model of neo-liberal economics.

Globalization as an economic, industrial, and commercial force has been around for a long time. Baldwin and Martin (1999) assert that "the world has seen two waves of globalization in the past 150 years, and in some ways, the world of 1914 was more tightly integrated than ours today" (p.3). According to these authors, the first globalization process evolved from 1870 to 1914 and was interrupted by World War I. 
The second globalization started years after World War II, about the late 1960s, and has gained momentum until today. In both globalization waves, there is a significant and growing pattern of trade, human migration, capital flows, and expansion of markets.

What appears to be different, however, are the social and cultural contexts during the second half of the $19^{\text {th }}$ century and today. During the first historical period, the majority of the world population was rural and poor. Today, the second globalization is dominated by urban centers, and the world is stratified and divided between rich and poor nations.

An additional argument which addresses the nature and ideological roots of globalization helps to conclude that globalization does not imply major novelty as a form of social and economic organization. Sweezy (1997) explains that globalization is "a process that has been going on for a long time, in fact ever since capitalism came into the world as a viable form of society four or five centuries ago" (p.1).

Teeple (2000) also refers to the ideological basis of globalization that connects the process to social and political consequences. Globalization, he argues, can be seen as the triumph of capitalism, that is, as the ascendance of economics over politics, of corporate demands over public policy, of the private over the public interest, of the transnational corporation and its global framework over the national state. It represents the approaching completion of the capitalization of the world (p.196).

What then, are the consequences of this global economy propelled by capitalistic principles upon social development?

\section{Social Consequences of Globalization}

Globalization has been mentioned as the most fundamental redesign and centralization of the world's political and economic arrangements since the Industrial Revolution (Mander, 1996). This process has allowed the unregulated expansion of the capitalist system which, in control of new technologies, has taken the opportunity to dominate new sources for capital accumulation and profit.

The initial steps of the current international economic recession will likely continue to bring about accelerated changes in the global economy, and the adoption of neoliberal policies will continue to challenge social development defined as planned intervention of national states. The velocity of change is currently motivated by corporate interests, the influx of foreign investments, high debts, and new relations of domination and global capital hegemony.

The present financial crisis will likely continue to increase the numbers of mergers and corporate alliances throughout the world. Business alliances and acquisitions are 
announced daily by U.S. companies trying to seek larger markets and expand the scope of their operations. In Europe, Asia, and Latin America, these corporate deals will continue to grow and will likely include more industries and countries.

According to Elliot (2000), globalization is "the most advanced form of capitalism (for now)." He also remarks that "capitalism is the greatest producer of wealth that the world has ever seen, but it is a profoundly destructive force, too" (p.2).

The expansion of markets and protection of territories have dominated international relations in modern history. Far from being an open exchange of goods and services, trade has been traditionally used as a political tool and linked to hegemonic purposes of world powers. The rapid expansion of global markets fosters the utilization of trade as a weapon to control national economies, industrial sectors, and smaller countries according to the interests of transnational businesses and global companies.

Industries such as telecommunications, computer technology, and international financing have experienced staggering growth and decline in recent years. Factors explaining growth are, among others, the economic revival after the Asian crisis, financial constraints of other national economies, business mergers, and concentration of ownership. The cyclical nature of the market economy, however, also involves crises, as demonstrated by corrections of the stock markets in the U.S., Europe, and Asia during the first semester of 2001 and also in more recent years. In the global economy, nevertheless, this up-and-down of growth and crisis contributes to further concentration of world financial resources in fewer hands and with limited norms and regulations.

The institutionalization of agreements, norms, and procedures administering free trade issues is relatively new and emerges with regional trade agreements and government-supported international organizations such as the North American Free Trade Agreement (NAFTA) in 1994 and the World Trade Organization (WTO) in 1996. It has been argued that the WTO has a powerful enforcement structure that jeopardizes national autonomy dealing with development strategies and government investments in the areas of health, finance, and education. Morris (2000) remarks that "the WTO is beginning to look like a new-world government." It only allows nations to enact legislation weaker than any global standard, and "when the WTO rules against a country, that country must amend its domestic laws" (p.17).

According to this author, the long-term problem of WTO management of world economies and policies that critically affect domestic factors of national development is that "the new planetary constitution (implanted by WTO) includes no Bill of Rights and offers no democratic process for change" (p.17).

Another viewpoint suggests that global integration today is based on continuous technological innovations, globalization of investments, and consolidation and control of larger markets. An ideological and cultural agenda emerges from the culture of 
capitalism to control and exploit resources, as well as to dominate markets and society. As Robbins (1999) suggests:

"The culture of capitalism is being exported to all parts of the globe. Yet few people are aware of how the culture works and how it affects our lives and those of people all over the world. The culture of capitalism purposefully masks from its members the problems that result from its maintenance and spread." (p.8).

The ability of some nations, however, to become fully integrated in the 'global web' varies according to levels of development and the hierarchical nature of the globalization process. Thus, the impact of globalization on the Third World poses critical questions regarding global inequality and international stratification.

Increasing globalization has influenced changes in investment patterns and movement of capital among regions and countries. These shifts have broadened the gap in the division of wealth among nations and accentuated the differences between the industrial and agrarian societies and between rich and poor countries.

Wagar (1991) reported that in 1990 the poorest $70 \%$ of the world's population earned only $7 \%$ of its income, while $30 \%$ earned the remaining 93\%. Dayal and Lobe (1995) stated that by mid-decade these conditions of income inequality had worsened as over one billion people lived in absolute poverty with their earnings of less than one dollar per day. According to Forbes Magazine, the top 358 billionaires had a combined net worth equal to the total income of the bottom $45 \%$ of the world's population.

It could be argued that these ideological bases of globalization help to connect the globalization process to social and political consequences affecting the international community. According to Midgley (1997), the result of this process of capital growth and profits for some individuals but limiting the chances of social improvement for the majority is what has been known as a form of "distorted development."

Over the last few years, however, there have been an increasing number of globalization activities. The direction which emerges from these massive expressions of protest is towards a new international social movement against the risks and perils of corporate powers. Although the voices of protest and resistance are still largely spontaneous and without strong political clout to alter government decisions and business influences, the anti-globalization activism is clearly becoming an anticapitalistic message and a global call for the defense of human rights and social development. The need for regulating financial global markets has gained attention at various forums of the United Nations and representative bodies of the international community.

The ideological struggle between capitalism and other forms or programs of economic, social, and political organization seems to converge towards a new global agenda 
oriented towards a new international community. According to Teeple (2000), "The struggle to change oppressive conditions can no longer be framed in strictly national terms because the nation-state is more or less rapidly losing its integrity as a system. With globalization, national forms of struggle are increasingly less effective against global corporate demands" (p.195).

\section{A System Perspective for Sustainability}

The Declaration on the Right to Development, adopted on December 4, 1986, enhances the value and worth of all human beings. It is also from this perspective that the Right to Development is recognized as an inalienable human right considering that the person is the central subject of the development process. From a world systems perspective and cognizant that wars and conflicts are serious barriers to maintain human and development rights, the United Nations sustains that international peace and security are essential elements for the realization of those rights.

Among the most prominent provisions recognized by the Declaration on the Right to Development are the following:

- The promotion and encouragement of international cooperation in solving social, economic, and humanitarian problems;

- The prevention of discrimination and full observance of human rights and fundamental freedoms for all members of the world community; and

- The responsibility of states for creating and maintaining adequate conditions for the rights to development.

According to the Declaration, development implies active and free participation of all members of society as well as a fair distribution of economic benefits and social rewards. Individual and collective participation become, therefore, instruments of what the 1980's Brand Report on development considered the desirable social and economic progress and the re-shaping of organizational components of the social system. This notion of development places the process of change beyond the economic and financial forces and brings into full view systemic conditions that commonly have a profound impact in all areas of human activity.

The response of the social sciences and, more specifically, the role of sociology in providing adequate tools for the study and guidance of social change and development 
have been, at best, mixed. Early conceptual approaches with emphasis on evolutionary processes led to later perspectives focusing on modernization as a natural consequence of industrial and economic growth. In both cases, results have been limited in the practical world of development (or lack of it) as much as in generating valid and universal knowledge applicable to all social systems. An additional internal issue of the discipline has been an unproductive debate and false dilemma between the "theoretical" versus the "applied" approaches of sociology. While those in the academic barricades of concepts and theories may have neglected the need for relevant information for formulating policy and directing change, some prominent sociologists of the past and practitioners in the camp of applied social science searched for 'usable knowledge' to deal with systems change and development.

\section{Sociology and 'Usable Knowledge'}

A little more than a century ago (1895), Max Weber, in his inaugural address at the University of Freiburg, expressed his thoughts about the purpose of sociology and stated that if "our work is to have any meaning, it lies, and can only lie, in providing for the future, for our descendants" (Weber, 1994). This statement is certainly remarkable in view of its similarity with the current concept of sustainable development, defined by the Brundtland Commission in 1987, as development that meets the needs of the present without compromising the ability of future generations to meet their own needs.

Although Weber in his pioneering book On the Methodology of the Social Science vigorously emphasized the concept of 'value-free research' (or free of the values and biases of the researcher), he strongly promoted the need to recognize the values of the society being studied to strengthen and improve it. Social values, then, as far as they help to determine what is desirable and shape individual behavior and social action, clearly relate to the processes of change and development. In reference to this relationship, Weber states:

"Truly empirical sociological investigation begins only with the question what did and still does motivate the individual members of the community to conduct themselves in such a way as to bring about the creation of this "community" and to ensure its continuation." (Weber 1962, p.29)

Weber considers values to be a driving force in societies, as illustrated also by his works The Protestant Ethic and the Spirit of Capitalism; and The Theory of Economic Organization. Today, the importance of values to understand society remains central to Sociocybernetics (Parra-Luna, 1998). Social values as axiological constructs orient human behavior and help society broaden the concept of development to include social 
equity, human rights, and social justice as essential ingredients to build stronger relations in a social system.

Efforts to understand parts of society in terms of relationships to the whole system (Weber, 1962) have challenged sociological theories and research since its origin. Different approaches, however, have occasionally diminished and even neglected some of the practical issues of applied research with a focus on the triangle composed by the elements of knowledge, understanding, and solutions of social problems.

Over sixty years ago, Robert S. Lynd (1939) raised the question, "Knowledge for what?" This basic question helped him and his students define the role of sociology and other related disciplines in a rapidly changing society. For this American sociologist, "If social science is to be free to be science, it must have the courage to fight for its freedom from the dragging undertow of a culture preoccupied with short-run statements of long-run problems" (p. 203).

Lynd's analysis of his time serves almost as a preview of many social problems still present in the United States and other nations. As a consequence, he sees the role of sociology as a tool for exploring and learning about the social system and its relationships as well as an organizing force for individual and collective action. He observed social change as a challenge for action, claiming:

"We are struggling to live today in a contracting world in which novel or upsetting things are happening all about us with startling speed and coerciveness... ...capitalism is in decline and democracy is on the defensive. The question our culture appears to confront is not 'shall we change?' but 'how can we contrive change extensive enough and rapid enough, however radical its innovations, to enable basic human values to survive?" (p. 207)

The list of social problems of a lagging system studied by Lynd six decades ago appears quite relevant in our world today, especially for sociologists. For him, the problems characterized then by a lack of an integrated world vision, the absence of political will, and the power of interest groups to avoid adequate policies are the best descriptors of basic imperatives for change and development. Four areas of central concern that connect with today's social development imperatives emerge from Lynd's assertions:

\section{(1) The need for developmental plans and strategies for action.}

According to Lynd, a major purpose of sociology is scientific discovery, but new knowledge must be connected to eliminate the gap between social problems and their solutions. Social science, he says, should "discover where and how large-scale planning and control need to be extended throughout the culture so as to facilitate the human ends of living" (p. 209). 


\section{(2) The case for change and improvement.}

A second area of major systemic problems identified by Lynd includes poverty, inequality, and discrimination. In his opinion, these problems undermine the values of democracy as a viable form of organization and reveal conditions of political apathy and generalized ignorance on civic affairs. As a result of his sociological analysis, Lynd made a strong case for change and improvement in the social and political arenas. "If democracy is to continue as the active guiding principle of our culture," he argued, "it will be necessary to extend it markedly as an efficient reality in government, industry, and other areas of living"(p. 215). Failure to achieve this objective would likely encourage the desire to abandon a purely formal democracy in favor of some other operating principle.

\section{(3) Global problems calling for global solutions.}

One persistent question for sociology throughout history refers to what kind of system would be more desirable, fair, and better equipped to sustain growth and quality of life for all. Judging the severity of social, economic, and political problems affecting today's world, it can be argued that present models and formulas have failed to keep peace and avoid wars, to feed the people and eliminate starvation, to provide education and to diminish ignorance.

Again, Lynd's observations conducted in the years following the Great Depression of the 1930s and anticipating the problems surrounding World War II focused attention on the inadequacy of capitalism as a socially efficient economic model. His critical analysis includes an invitation to the social sciences to continue analyzing the economic and social organization from a systems' perspective. He remarks,

"...capitalism does not now operate, and probably cannot be made to operate, to assure the amount of general welfare to which the present stage of our technological skills and intelligence entitle us; and other ways of managing our economy need therefore to be explored."(p. 220).

In light of the extent to which economic globalization based on neo-liberal economic ideas and capitalistic practices appear to have failed, so far, to bring basic conditions of equity and well-being to all nations and societies, Lynd's comments of over six decades ago seem to gain in prominence and actuality. Today's global problems, therefore, clearly call for global solutions to make society a sustainable system. 


\section{(4) Sociology's responsibility to focus on change.}

Lynd's perspective of the role of sociology appears to point towards a discipline that is, or could be, both an 'active' inquiry of social reality and a 'pro-active' analytical tool to study and steer social change. He recognizes change as a pivotal process of society.

Sociological knowledge, therefore, cannot be conceived as separate from its application and impact on a changing social system. The fact that some traditional approaches of the discipline have managed to stay away from the practical needs of change and development has not silenced the voices of those arguing for a better balance between theoretical and applied knowledge for problem-solving endeavors.

Given the interwoven nature of global social problems, there are three important guiding principles to consider:

- First, a systems perspective that requires an integrated vision and analysis of relationships in complex social systems. Sociocybernetics appears well positioned to satisfy the demands of usable knowledge in this area.

- Second, a problem-solving approach that involves creating conditions for change with clear definitions of outcomes and expectations of improvement.

- Third, social development as an organizing principle. This includes the notion of applied knowledge to satisfy social needs and contribute to the solution of social problems. Consequently, social development is defined here as "a process of planned social change designed to promote the well-being of the population as a whole" (Midgley, 1999).

\section{Sociocybernetics and Social Development}

Sociocybernetics emerges as one of the most promising theoretical and practical endeavors to confront the analysis of complex social systems as well as a methodological tool for evaluating social problems.

The intellectual and scientific capacity found in the cybernetic tradition of Bertalanffy (1975), Ashby (1956), Wiener (1948), Luhmann (1990), Beer (1994), and others permits us to approach social and organizational problems from both theoretical and practical perspectives. Also, the contributions made by Buckley (1967), Bailey (1997), Geyer (1999), and a number of scholars studying modern systems theory seek an adequate balance between sociological theory and the concrete consequences of individual and organizational decisions. 
Social processes and systems' problems are far from being static. On the contrary, they can be changed and improved if knowledge is expanded, behavior is modified, and proper action is taken. Knowledge about society and a better understanding concerning the organization of complex social systems could certainly be invaluable for the task and goals of social development. In a sense, social problem solving may well be considered an integral part of systems analysis, the central objective of sociocybernetics.

At the beginning of a new century, and a new millenium, it is appropriate for sociocybernetics to review both its place in sociology and the problems upon which it is focused. Sociocybernetics deals with complex (sometimes referred to as second order) systems, especially including the role of information and information transfer, as applied to the analysis of social systems. The use of the sociocybernetic paradigm to explain complex social phenomena is especially important in light of problems of development, globalization, and a number of other processes affecting society today. Sociocybernetics may offer sufficient depth and breadth to examine issues of change, organizational diversity, and policy implementation within the context of a dynamic and complex social system. The systems approach may well provide us with the tools to explain the present and explore future improvements.

The analytical elements of earlier systems theory emphasized the notions of social control and systems' equilibrium. As Buckley (1967) suggests, the implicit notion is that mechanisms of defense, adjustment, and deviance control are "aimed at the adaptation of individuals to the dominant structure" (p. 30). This early conception of systems theory rests on the ideas of stability and equilibrium, which may lead to rather simplistic explanations of social systems as resistant to change. Contrary to this static notion, Geyer and van der Zouwen (1991) state that "sociocybernetics inevitably tends to concentrate on problems associated with change and growth, rather than with stability." Geyer (1995) returns to this issue, arguing that "Since complex modern societies -as compared to simpler ones -- are highly dynamic and interactive, and thus change at accelerated rates, they are generally in a far-from-equilibrium situation" ( $p$. 24).

Notions of change in terms of transformation and improvement as well as the premise of growth implying development and progress appear in the thoughts and writings of various authors in the field of sociocybernetics. For instance, Bertalanffy (1968), a pioneer of the General Systems Theory, recognizes early the importance of the individual and values as key elements for change in social systems. He implicitly accepts the recursive nature of social systems as recurrent interactions that permit transmission of values and the inherent dangers of the control of communicating those values. For him, such control tends to minimize creativity and change, and, when that happens, the system loses not only opportunities for all its members but also "the 
specifically human features of responsibility, free decision, and true human values" (pp.125-126).

Buckley (1967) also describes the advantages of modern systems theory in terms of the capacity of the social systems to change, adapt, and modify their structures.

\begin{abstract}
"Systems Theory transcends the equilibrium reference... in recognizing the very different problem of the complex, open, adaptive system which depends not simply on mutual relations of parts, but on very particular kinds of mutual interrelations. In addition, the important problems of primacy of some parts over others and the varying degrees of connectedness of some parts of the system to others are made subject to analysis" (p.79).
\end{abstract}

\title{
6. Sociocybernetic Concepts for Change and Development
}

Some key concepts pertaining to General Systems Theory that are relevant to the processes of social change and development include, among others, the notion of autopoiesis, self-reference, system differentiation, recursivity, and structural coupling.

Maturana and Varela (1980) introduced the concept of autopoiesis, describing living systems as autonomous, self-referring, and self-constructing units. The concept of autopoiesis refers to the capacity of systems to define and maintain their identity and self-generate their components. Although they first developed their conceptual constructs from a biological perspective, the progression and diffusion of their research has unveiled fundamental questions and propositions of importance to systems theory.

While their later works appear well-connected to issues of concern for sociocybernetics in studying social systems, there have been some questions about the applicability of autopoiesis to all types of social systems. Biggiero (2001), for instance, asks whether firms and commercial organizations are in reality autopoietic systems. He sustains that as autopoiesis is basically defined as "self-production of the invariant organization of a closed network" (p.127), it would follow that systems such as firms and business organizations are not autopoietic units (p.125).

Biggiero considers the characteristics and conditions defining autopoiesis for biological living systems too restrictive if applied to social systems. He concludes that second-order cybernetics can provide valuable help to analyze and understand social systems "if concepts like self-organization, self-reference, and autonomy are interpreted as a question of degree and not as on/off conditions" (pp.134-135).

According to Maturana and Varela, however, autopoiesis and networks of relationships are essential elements in defining a social system with potentials for 
change and development. They affirm that "the structure of a society as a particular social system is determined both by the structure of its autopoietic components and by the actual relations that hold between them while they integrate it" (p.xxv). Systems, therefore, owe their basic identity to the set of inter-component relationships that define their organization. In addition, it is through a number of recurrent interactions between two or more systems, or the 'structural coupling' between systems, that changes take place in each of the systems involved.

Hornung (1999) discusses the concept of structural coupling and its relevance for social systems underlining the notion that human beings as recursive systems engage in interactions and communication, organize communities, and are 'capable of reflective information processing' that constitutes elements of consciousness. Structural coupling, then, connotes the attributes of cognition, consciousness, and value orientations that are reflected in change and co-adaptation of connected social systems.

Systems identity as well as systems differentiation are both linked to the selfreferential capacity of the system that permits a unit to determine what is unique and different from other systems. Social differentiation, then, may be observed as a condition characterized by higher complexity in a system as a result of change in its components and also changes in related systems. Social and cultural changes involve, therefore, a higher degree of differentiation and complexity in systems and their environments.

The recursive nature of systems allows, and even requires, recognition of the importance of each individual within the social system. Recognition of this fundamental aspect of social systems carries with it the acceptance of the importance of social values usually viewed connected to purposive change or development. According to Maturana and Varela (1980),"In man as a social being, all actions, however individual as expressions of preferences or rejections, constitutively affect the lives of other human beings and, hence, have ethical significance"(p.xxvi). This incorporation of values into the study of social systems allows them to affirm: "All kinds of societies are biologically legitimate. Yet not all are equally desirable as systems in which an observer human being may wish to live"(p.xxix). This is indeed an interesting remark about social values applicable to conditions of development or under-development in the world today.

Values, or the fundamental shared beliefs of a society, are the single most important factor to drive social change (Beer, 1975; Meadows, 1993). Parra-Luna (2000) asserts that "the needs/value binomial becomes the essential raw material for sociological analysis, needs as a factor of motivation as well as values as a factor of satisfaction" (p.1)

In his work on the development of an axiological systems theory, Parra-Luna (2001) sustains that values are essential in order to meet individual and collective needs. 
Consequently, he affirms, "the logical aim of any society, then, can be no other than to best satisfy the individual needs of each and every one of its members..." (p.7).

Parra-Luna (2000) stresses, however, that values are shaped and voiced by the ruling elite. He suggests that the elite decide "what, when, and how the system should produce," and that the interests of those with power overshadow the needs of the rest of the population. A particular strength of Parra-Luna's axiological perspective in dealing with issues of social inequalities and systems'exclusion is the recognition that every human being counts if a society is to perform effectively. The axiological systems theory is fundamentally humanist and inclusive. It considers all persons, or as ParraLuna (2001) affirms, "each and every one of the individuals that comprise (a system), insofar as they are units of decision with self-awareness of their rights and obligations in society and the ultimate aim of social activity itself' (p.4).

A similar viewpoint is also expressed by Maturana in the preface of his book Autopoiesis and Cognition (Maturana and Varela, 1980) where he explains:

\begin{abstract}
"A human being that through his interactions with other human beings participates in interactions proper to their social system in a manner that does not involve his autopoiesis as a constitutive feature of it, is being used by the social system but is not one of its members. If the human being cannot escape from this situation because his life is at stake, he is under social abuse" (p.xxix).
\end{abstract}

A large segment of the world population cannot be expected to continue living indefinitely under social abuse. If one accepts that the statistics on education, work, and income reflect a non-sustainable situation for those in poverty and living in conditions of marginality, then one must also accept that the situation is not contributing to the realization of society as an adaptive, or viable, system.

\title{
7. The Viable System Model
}

The notion of viable system developed by Stafford Beer throughout a long and distinguished career illustrates the connection between theory building and practical application of systems research. Beer (1975) provides an articulated application of the analysis of social systems to problems of national development and other units through what he describes as the Viable Systems Model (VSM). He sees sociocybernetics as more than a diagnostic tool with which to point out the flaws in present society. The Viable Systems Model presents a paradigm for social analysis and directed social change: 
"If dogma, doctrine, and expertise fail to give effective answers, then what criterion of effectiveness shall cybernetics use? My answer to this question is: the criterion of viability. Whatever makes a system survivalworthy is necessary to it." (p. 426).

The "Viable System Model" is based on key sociocybernetic principles that include the processes of social change, communication, organization, social action and development. The operational dynamics of this model distinguished the following components fostering system's sustainability:

(1) Scientific and Technical elements for development plans

(2) Communication between government and the people

(3) Social learning to solve problems

(4) To facilitate ample social participation

(5) To promote social development

Beer discusses the importance of planned change as a tool for improvement of all members of a social system in Platform for Change (1975), The Brain of the Firm (1972), and other sources. An effort to apply the VSM was conducted in Chile during Salvador Allende's socialist government in the early 1970s (Menanteau, D. 1999).

Other applications of Beer's Viable System Model to issues concerning change and organizational development are discussed by Espejo and Harnden (1989). Over the last two decades, applications of this model have covered a variety of areas from managerial and organizational issues of industry and businesses to social and political problems of national development. The geographical diversity of these studies is as vast as the world map with projects conducted in England, Europe, Canada, the United States, Latin America, Australia, and New Zealand (Beer, 1989).

According to Beer, viable systems are defined in terms of their autonomy and ability to maintain their identity within a common environment. This means that a viable system is connected to other viable systems, making communications and relationships the vital linkages and primary conditions for viability. The interaction and network established between viable systems is explained by the theorem of recursion that determines that "In a recursive organizational structure, any viable system contains, and is contained in, a viable system" (p.34). The recursive nature of social systems represents one of the key rules of the model for social change and development. 
Beer (1994a) also proposes three organizational principles that direct and facilitate the recursive relationships of all subsystems.

The first principle refers to systems' complexity, called variety, and the organizational and managerial problems affecting social cohesion as a result of complexity. In social development programs, the number of diverse elements in a system that measure the condition of variety may constitute a major barrier if it is not carefully considered and controlled. The problem is certainly a problem of systemic complexity as the model recognizes the existence of managerial, operational, and environmental varieties.

The second principle focuses on the notion of 'design' which involves a number of organizational elements embedded in planning, policy formulation, and action implementation. From a social development perspective that recognizes the processes of goal setting and systems' intervention to carry out a program, this second principle becomes highly relevant.

The third organizational principle declares an explicit concern for the people who as recursive living systems constitute essential components of the viability of the entire system. This point is illustrated by Beer (1994b) as he tells the story of the application of the VSM in Chile that although it was officially called Project Cybersyn, it was popularly known in that country as 'the People Project.' This new name alluded to one of the main purposes of the project, which was to examine the systems dynamics of the interaction between the government and the people.

As mentioned by Espejo (1989), who was one of the closest collaborators of Beer in Chile during the short life of Project Cybersyn, the Viable System Model "offers a paradigm for problem-solving. Its understanding offers a mental tool to approach the creation and design of effective context for the participation of people in human activities" (p.98).

The sociocybernetic experiment in Chile demonstrates that even in times of political and economic difficulties such as that country experienced in the early 1970s or, perhaps, under these types of social constraints, is when sociocybernetics may best contribute to build bridges and establish linkages between sociology and social development. To move forward in this direction, it seems that there are two essential factors simultaneously emerging: First, the challenges for change and development are visible and urgent globally. Second, the conceptual and methodological tools of sociocybernetics appear to be better equipped than other sociological perspectives to generate knowledge about complex systems and possibly 'steer' the processes of change and development. 


\section{Conclusions}

The current financial crisis and economic recession will likely continue to demand changes in the global economy and society. Abuses and failures of neo-liberal policies will continue to underline the importance of new ideas and policies and programs pursuing social development.

The dominant presence and influential powers of transnational corporations have shown how vulnerable national governments have become. Global ties to international financial interest and restrictions of national states to deal with their internal social and economic problems have enormous repercussions in their abilities to invest in social welfare.

The lack of social development strongly supports the notion that social problems today are global problems. Poverty affects at least 3 billion people who live with less than 2 dollars per day, and over 300 million children suffer hunger. Even in some industrial nations, there are over 100 million people in poverty.

Global social problems constitute a serious challenge to social sciences and especially to sociology as they affect social organization and human behavior. It is imperative, therefore, to keep working on a conceptual framework which will provide a global system perspective capable of increasing our understanding of social complexity and sustainability.

\section{References}

Ashby, R. (1956). An Introduction to Cybernetics. London: Chapman \& Hall.

Baldwin, R.E. and Martin, Ph. (1999) 'Two Waves of Globalization: Superficial Similarities, Fundamental Differences'. National Bureau of Economic Research, Working Paper 6904.

Beer, S. (1975). Platform for Change. New York: Wiley \& Sons.

Beer, S (1989). The Viable System Model. New York: John Wiley \& Sons.

Bertalanffy, L. (1975). Perspectives on General Systems Theories. New York: George Braziller.

Bigelow, J. (1964). Address to the American Society for Cybernetics. October 16. Washington, DC.

Buckley, W. (1967). Sociology and Modern Systems Theory. N.J.: Prentice-Hall. Englewood Clifts.

Dayal, J. and Lobe, J. (1995) 'Poverty-Global: Poor People, Rich Banks and Good

Intentions', Interpress Third World News Agency, Oct.21.

Dechert, Ch. (1966). Social Impact of Cybernetics. London: Univ. of Notre Dame. 
De la Rúa, F. (2000) 'La equidad, base para un nuevo camino hacia el desarrollo enArgentina'. In Muñoz, H. (Editor), Globalización XXI (pp.55-60). Aguilar: Santiago, Chile.

Elliot, M. (2000) 'Lessons from the Battle of Seattle'. Newsweek International, 2000, Jan.1.

Gaviria, C. (2000) 'El nuevo multilateralismo hemisférico en el marco global'. In: Muñoz, H. (Editor), Globalización XXI (pp.107-118). Aguilar: Santiago, Chile.

Geyer, F. (1995). The Challenge of Sociocybernetics, Kybernetes , 24, 4:6-32.

Geyer, F. \& Van der Zouwen, J. (2001). Sociocybernetics: Complexity, Autopoiesis, and Observation of Social Systems. Connecticut: Greenwood Press.

González, F. (2000) 'Economía global y progreso global'. In Muñoz H. (Editor), Globalización $X X I$ (pp.27-53). Aguilar: Santiago, Chile.

Lagos, R. (2000) 'Hacia un nuevo consenso social internacional'. In Muñoz, H. (Editor), Globalización XXI (pp.19-25). Aguilar: Santiago, Chile.

Luhmann, N. (1995). Social Systems. California: Stanford University Press.

Luhmann, N. (1990). Political Theory in the Welfare State. N.Y.:Walter de Gruyter.

Mander, J. (1996) 'The dark side of globalization', The Nation, July 15.

Maturana, H. and Varela, F. (1972). Autopoiesis and Cognition. Boston: D. Reidel.

Maturana, H. and Varela, F. (1988). The Tree of Knowledge, Boston: New Science Library.

Menanteau-H, D. and Marcuello-S, Ch. (2008) 'Una Perspectiva Sociológica para la Acción Social y el Desarrollo: Avances de la Sociocibernética', Revista AAustral de Ciencias Sociales. Universidad Austral de Chile.

Midgley, J. (1997). Social Welfare in Global Context. California: Sage Publications.

Monckeberg, M.O. (2001) El Saqueo de los Grupos Económicos al Estado Chileno. Ch.1, El Mostrador, 4/21/01. (www.elmostrador.cl)

Morris, D. (2000) 'This Isn't your Father's Fee Trade', The New Rules, Minnesota:

Institute for Local Self-Reliance. (Winter) pp.16-17.

Parra-Luna, F. (2000). The Performance of Social Systems, New York: Kluwer Academic/ Plenum Publishers.

Paul, G.S. and Cox, E. (1996). Beyond Humanity: Cyberevolution and Future Minds. Charles River Media.

Robbins, R. (1999) Global Problems and the Culture of Capitalism, Boston: Allyn \& Bacon.

Sweezy, P. (1997) 'More (or Less) on Globalization', Monthly Review, September, pp.1,4.

Teeple, G. (2000) Globalization and the Decline of Social Reform. New York: Humanity Books.

Ulrich, W. (1994). Critical Heuristic of Social Planning. New York: John Wiley \& Sons.

United Nations (1996). Human Development Report. New York: Oxford Univ. Press. 
Globalizatiom and Distorted Development

Wagar, W. (1999)The Next Three Futures: Paradigms of things to come, New York: Greenwood Press.

World Health Organization (1995). World Health Report. 